Int. J. Electrochem. Sci., 14 (2019) $9671-9681$

\title{
A Mechanistic Study of Corrosion of Graphene and Low zinc- rich Epoxy Coatings on Carbon Steel in Salt Environment
}

\author{
Shengrong Wang ${ }^{1,2, *}$, Jianwei Yang ${ }^{1,2}$, Jianping Cao ${ }^{1,2}$, Lijun Gao ${ }^{1,2}$, Chenxi Yan $^{1,2}$ \\ ${ }^{1}$ Shougang Research Institute of Technology, Beijing 100043 \\ ${ }^{2}$ Beijing key Laboratory of Green Recyclable Process for Iron \& steel Production Technology, Beijing \\ 100043) \\ *E-mail: wangshengrong@126.com
}

doi: $10.20964 / 2019.07 .17$

Received: 9 February 2019 / Accepted: 21 April 2019 / Published: 30 August 2019

The effect of graphene on zinc-rich epoxy coating comprised of $40 \mathrm{wt} \% \mathrm{Zn}$ has been studied.The potential-time measurement, electrochemical impedance spectroscopy (EIS), salt spray fog and UVaging cyclic aging test and scanning electron microscopy (SEM) were used to characterize the protection performance of coatings. The results show that the zinc-rich epoxy coating reinforced with $2.0 \mathrm{wt} \%$ graphene has greatly improved the corrosion protection of coating. Also, the permeability of zinc-rich epoxy coating can be improved by adding adequate amounts of graphene. Graphene nanosheets could enhance the conductivity of zinc particles by introducing the graphene into zinc-rich epoxy coatings and improved the utilization of zinc powders, finally, the life of zinc-rich epoxy coating was prolonged.

Keywords: Zinc-rich epoxy; Graphene sheets; Corrosion protection

\section{$\underline{\text { FULL TEXT }}$}

(C) 2019 The Authors. Published by ESG (www.electrochemsci.org). This article is an open access article distributed under the terms and conditions of the Creative Commons Attribution license (http://creativecommons.org/licenses/by/4.0/). 